\title{
DAILY DEMANDS IN PRIMARY CARE: THE VIEW OF HEALTH PROFESSIONALS AND USERS
}

\author{
Tatiana Vasques Camelo dos Santos ${ }^{1}$, Cláudia Maria de Mattos Penna ${ }^{2}$
}

\footnotetext{
${ }^{1}$ Ph.D. candidate, Graduate Program, Universidade Federal de Minas Gerais (UFMG). Minas Gerais, Brazil. E-mail: tativas@ globo.com

2 Ph.D. in Nursing Philosophy. Associate Professor in Nursing, UFMG. Minas Gerais, Brazil. E-mail: cmpenna@enf.ufmg.br
}

\begin{abstract}
In this qualitative case study based on the Comprehensive Sociology of Everyday Life, the aim was to describe the daily situations that require the use of health services from the perspectives of health care professionals and users. We interviewed 15 professionals and 17 users at three Family Health Team units in a city in the State of Minas Gerais State, using a script with open questions. The data were subject to content analysis. It was shown that the demands result from a combination of the population's social, individual and cultural factors. Care is delivered based on the users' spontaneous and, for the professionals, usually, the users are interested in a consultation, generally medical, including referral to specialists and free distribution of medicines. These findings indicate that health care needs to transcend the biological body and understand other dimensions that comprise the users' daily lives in search of problem solving.
\end{abstract}

DESCRIPTORS: Health services accessibility. Health services needs and demand. Primary health care.

\section{DEMANDAS COTIDIANAS NA ATENÇÃO PRIMÁRIA: O OLHAR DE PROFISSIONAIS DA SAÚDE E USUÁRIOS}

RESUMO: Estudo de caso qualitativo fundamentado na Sociologia Compreensiva do Cotidiano, com objetivo de descrever as situações diárias que demandam a utilização dos serviços de saúde a partir das perspectivas de usuários e profissionais de saúde. Foram entrevistados 15 profissionais e 17 usuários de três unidades de Equipe Saúde da Família de um município do Estado de Minas Gerais, a partir de um roteiro de perguntas abertas. Os dados foram submetidos à análise de conteúdo. Constatou-se que as demandas resultam da conjugação de fatores sociais, individuais e culturais prevalentes na população. Os atendimentos ocorrem a partir da demanda espontânea dos usuários e, para os profissionais, o interesse que se apresenta é por consulta, geralmente médica, com encaminhamento para especialistas e distribuição gratuita de medicamentos. Esses achados apontam que o cuidado em saúde precisa transcender o corpo biológico e compreender outras dimensões que compõem o cotidiano dos usuários em busca da resolutividade.

DESCRITORES: Acesso aos serviços de saúde. Necessidades e demanda de serviços de saúde. Atenção primária à saúde.

\section{LAS DEMANDAS DIARIAS DE ATENCIÓN PRIMARIA EN LA SALUD: LA MIRADA DE PROFESIONALES Y USUARIOS}

RESUMEN: Este es un caso de estudio cualitativo basado en la Sociología Comprensiva de la vida cotidiana cuyo objetivo fue describir las situaciones cotidianas que requieren el uso de los servicios de salud desde la perspectiva de los usuarios y los profesionales de la salud. Se entrevistó a 15 profesionales y 17 usuarios de las tres unidades del Equipo de Salud de la Familia en un municipio del Estado de Minas Gerais a partir de un guión de preguntas abiertas. Los datos fueron sometidos a análisis de contenido. Se encontró que las demandas resultan de la combinación de factores sociales, individuales y culturales prevalecientes en la población. Las sesiones tienen lugar a partir de la demanda espontánea de los usuarios y para los profesionales, el interés que se presenta es una consulta, por lo general médica, con la derivación a los especialistas y la distribución gratuita de medicamentos. Estos resultados indican que el cuidado de la salud debe ir más allá del cuerpo biológico y comprender otras dimensiones que conforman la vida cotidiana de los usuarios en la búsqueda de la solución de problemas.

DESCRITORES: Accesibilidad a los servicios de salud. Necesidades y demandas de servicios de salud. Atención primaria de salud. 


\section{INTRODUCTION}

The proposal for a Unified Health System (SUS), organized at each governmental level, offering universal and equalitarian access, imposed a new organizational logic to restructure the care system. The first aspect to be highlighted is the transfer of the responsibility to offer basic health care services to cities, in a planned and organized manner, with a view to better care delivery to the population covered. The restructuring of this care supply includes primary care, through the Family Health Strategy (FHS), considered as the entry door into the system.

The FHS should be articulated with other health care levels in accordance with the user's needs. Its genesis is based on the paradigm change process, which is directed by the biomedical health care model, transferring the focus of attention to the family and community. In this changed paradigm, the work process centered on the user's interest is the factor that guides care practices. This clearly reveals the importance of care beyond the biological, comprising other dimensions, which demands knowledge on the historical background of each family, ${ }^{1}$ so as to unveil the subjectivities and singularities of the subjects involved in this care.

Some studies have evidenced, however, that despite the health care change discourse in distinct cities that have implemented the FHS, as effective teamwork that acknowledges comprehensiveness in seeing to the population's needs, inequalities in the health and disease process have not been overcome yet. It seems that the proposals for a hierarchized and complementary health care network, between the public and the private; attendance to an organized demand, without neglecting individual needs, delivered by an interdisciplinary team, centered on the clients and involving their co-participation in the search for solution to collective problems; inclusion and access to comprehensive practices have not been developed satisfactorily in the health sector. ${ }^{2-3}$

Mutual social relations among different actors permeate daily work at health services, which can determine distinct perspective between users and health professionals as to needs in disease and health. The reality of both dimensions is independent from their biomedical definitions and different representations and practices exist, which vary according to the society and culture of each community or family. It is highlighted that the biological reality of the disease, as identified by health professionals, often does not correspond to the patient's reality. In view of this assertion, the search for services is based on each individual's representation of his/her disease or its symptoms, as this experience is individual and always permeated by sociocultural and family issues. ${ }^{4}$

Precise calculations to measure the demand for health services or even define a population's actual health needs seem impossible. This requires research on the demands health services are confronted with, with a view to revealing the subjectivities needed when care is sought. This understanding can clarify the user population's mechanisms to access public health services or not, as well as the type of care and treatment they receive, contributing to reflections on the daily reality at services and the way they get organized to respond to the guiding principles of the health system in force. ${ }^{5}$

This study is an excerpt from a research on access and problem-solving ability in health, and is aimed at describing the daily situations that demand the use of health services, based on users and health professionals' perspectives.

\section{METHOD}

This qualitative and descriptive case study was based on the Comprehensive Sociology of Everyday Life. ${ }^{6}$ It was undertaken at three FHS units in Manhuaçu-MG. In the selection of the units, those with the largest number of registered families and which offered complete teams at the time of data collection were considered, including: physician, baccalaureate nurse, auxiliary nurses and community health agents. To apprehend different cultural and socioeconomic realities, data were collected at one rural, one urban and one mixed FHS unit that complied with the inclusion criteria.

Subjects were three baccalaureate nurses, three physicians, three auxiliary nurses and six Community Health Agents (CHAs), two from each unit, totaling 15 health workers, so as to represent professionals from the minimal team required at FHS units. To represent the users, subjects were addressed equitably among the health units until repeated and complementary observation was observed, that is, until data saturation occurred, ${ }^{7}$ totaling 17 subjects, all of whom were over 18 years of age.

The data were collected through interviews, applying a different semistructured script to each group of research subjects, which were audio-recorded and fully transcribed for further 
analysis. The interviews took place in November and December 2010 at the unit, upon appointment, except for two users from the rural region, who were visited at home during home visits the researcher accompanied as an observer, according to the respondents' choice at the time of the invitation. Also, observations were made in the waiting rooms and inside the units, registered in a field diary, including the description of events, people involved, dialogues, non-verbal behaviors, gestures, as well as the researcher's impressions about the data observed.

After the transcriptions, the data were submitted to content analysis, ${ }^{8}$ using systemized readings, interpreted to constitute categories and discussed in confrontation with the literature.

The study received approval from the Institutional Review Board at Universidade Federal de Minas Gerais, registered under number 0501.0.203.000-09. In compliance with National Health Council Resolution 196/96, data collection started after receiving formal authorization from the municipal health manager, and all subjects were invited to participate and signed the Informed Consent Form. The informants' anonymity was guaranteed. They were identified as follows: Nur (baccalaureate nurse), Phy (physician), AN (auxiliary nurses), U (users) and CHA (Community Health Agent), followed by a numerical code according to the order of the interviews.

\section{RESULTS AND DISCUSSION}

\section{The search for care based on individual de- mands: the view of professionals and users}

Based on data analysis, it is observed that most health care in the city departs from users' spontaneous demand: [...] consultation...they really come for the consultation! Everything you can imagine (CHA14); [...] medicines, a lot of prescriptions really [...] what most loads the unit is consultation, what they want a lot is to get medicines (CHA11); the user supports the professionals' finding: [...] I come here sometimes to pick up medicines, consultation [...] (U10). Hence, the interest is in consultations, generally medical, including forwarding to specialists, and free medication distribution, which in a way reaffirms the physician-centered model, focused on the disease.

As evidenced, the demands health services are confronted with comprise the translation of the individual needs felt and interfere in how health services are used, despite the incorporation of oth- er actions at the units. The care sought is still aimed at finding answers to the disease, guaranteed by the trust placed in examinations or a consultation with professionals in other specialties.

This finding is supported in another study that confirms some users' biomedical view on the actions that take place at health units, showing a trend to consume medical consultations to solve demands, as "the market imposes the consumption of technologies and deducts the notion of what translates a necessary need and a market need from the user's understanding. In addition, in the health area, the hegemony of the biological techno-care model (where the organization of work basically involves the consumption of hard technologies) and its century-long influence on the population determines this situation, resulting in a perception and understanding that the consumption of health technologies (exams, procedures and sophisticated treatments) means access to health". 9:104

Thus, it is observed that some users demand medium-complexity therapeutic, medication and diagnostic interventions, including specialized care delivery, beyond what primary care offers: [...] sometimes they arrive asking, look, I want to go to the head doctor, the eye doctor, they get in asking [...] or I want a complete exam...an ultrasound, an Xray, an endoscopy (Phy7). They come for the dentist, vaccination, routine exam, everything, they come for everything, in fact I think that they come for things I don't even know if that's here, because this kind of small unit, it's for primary care. They ask for a lot of specialist things, they feel a great lack (CHA12).

It should be highlighted, however, that some programs developed in primary health care, but focused on the control of diseases like hypertension and diabetes, or even prevention programs like vaccination, are widespread and accepted in the community. As consultations and medication distribution are part of the care protocol, users relate the use of health services to the supply of the actions developed in those programs: it is because of the high blood pressure, I am a diabetic, high cholesterol, high triglycerides [...] (U8); I have high blood pressure [...] I take medicine against depression, and it's rare that I feel bad, then I come (U11); just when I'm really sick... it's more for consultation, but not my family, my father and my mother are hypertensive and they go, because the unit provides the medicine (U17).

Thus, it is inferred that Family Health Units, characterized as the entry door to health services and responsible for putting in practice the prem- 
ises of primary health care, respond to individual demands and remain restricted to conducts that often prioritize disease treatment. It should be observed that Primary Care is characterized by "a set of health actions, in the individual and collective sphere, that cover health promotion and protection, disease prevention, diagnosis, treatment, rehabilitation and health maintenance. It is developed through democratic and participatory management and health practices, in the form of team work, directed at populations in well-outlines territories, for which the team takes responsibility in terms of health care, in view of the dynamics that exist within the territory these populations live in". ${ }^{10: 10}$

The care sought is still physician-centered though, which enhances the valuation of and demand for forwarding to specialists. This creates the impression that users have not been sensitized to the guiding principles of primary health care and tend not to seek other care forms offered at the FHS units, but demonstrate the need for diseasefocused interventions and therefore demand a specialist or an examination.

As highlighted, "the technological imperative of the $20^{\text {th }}$ century has been responsible for a trend towards specialization and towards the inferiority of generalist physicians". ${ }^{11: 32}$ This clearly reveals the challenge for professionals to bond with users, in response to their multiple complaints, which are not always merely biological, sometimes demanding care beyond what the team feels capable of offering, in the attempt to improve people's quality of life. This causes some degree of imbalance between primary care service users' needs and demands and the perception of what health professionals consider they need.

According to the respondents, users demand care mistakenly, generally influenced by the local culture: because, in fact, patients who come to the unit do not exactly have a disease, but I think that it is a cultural means for them (Nur9); it was to respond to those cases that really need to be attended to but, unfortunately, there's this low cultural level of the population, who need to visit the doctor for anything [...] people mix that up a lot, instead of seeking a doctor for what they need, they come and visit in vain, because there's the service, it's for free, they think the physician is here, makes a lot of money, and that his obligation is to deliver care, they sneeze and run to the unit, they can't wait to see if this sneeze will evolve, so it's culturally... so our care volume is very big... on average, I see 30 medical consultations per day [...] there are maybe five people who really need care when they come to the unit, perhaps five others you could see to quite easily, it's something that could wait, but it could be done there... not the rest! Most of the rest could wait [...] (Phy10).

It is reaffirmed that physician-centered care is focused on the disease, according to the professionals as well as the users. If, on the one hand, what is sought in daily care is a normative health practice, on the other, people's own rhythm of life cannot be standardized. Seeking health care means finding answers to one's affected needs, for which no immediate solution is known, so that a simple sneeze may not be that simple for the user. Therefore, a distinguished intervention is required, distant from Cartesian clinical practice, based on the request for diagnostic tests, highlighting the importance of knowledge about extrinsic factors, in view of health and disease determinants, which favor the appearance of the physical signs the users initially presented. ${ }^{11}$

The disease experience is culturally molded, which determines the way it is perceived and the routes followed to overcome it. It is known that the social context directly influences the way patients feel ill, whether through recurring and frequent trends in television media, which are so widely rooted in Brazilian culture, or through the status relation deriving from a certain diagnosis.

According to the professionals, the lack of clarifications about hygiene issues contributes to the appearance of worm infestations and also hampers the use of prescribed medicines, which influences the control and cure of several diseases: the pigsty problem really, of people you explain and they don't understand, continue having cats, dogs, pigs inside the house so, we've got this problem here, your see? There are two or three here whose blood pressure is really difficult to control, who need to go and live with their daughter or they won't take the medicine right (Phy11).

Nevertheless, it is questioned how this information reaches the users? It is a fact that daily health work depends on the population's behavioral changes through educative practices. As these changes do not always take place, the discourse of "blaming the victim" is reaffirmed, reducing the problem to the subject's individual behavior, without establishing relations with subjects' factors and external conditions, but which, in turn, determine the conditions of each. "Because, when discussions about the disease are broadened, they disclose the constant need for basic sanitation, in- 
cluding water supplies, measures that have more than proven their efficiency against contamination or relapses". ${ }^{12: 85}$

It is acknowledged, however, that the care users seek goes beyond the demands expressed, and comprises demands that are not formulated and are considered more subjective, related to social issues, which go beyond medicalization: hypertension and diabetes, headache and fever in children, but most are affective issues really. You see that people who want medication, they don't want medication, they want attention, mainly elderly patients, you see? (Phy11); look, to tell you the truth, there is a great lack here, despite fever, cough or headache, most consultations today are social issues, people who don't have anything to eat at home, and sometimes come to blow off steam, people who don't have anything to give to their children, who sometimes want medicines to put their children to sleep at home so that they don't go out to steal, so, patients' demands are really lacks (Nur12).

In view of the reality presented, reflections are needed on this diffuse suffering, which displays a range of symptoms, in addition to a lack of perspective in life, making users seek care at the service, where they expect to find answers for their living conditions. ${ }^{13}$ To see to them, care delivery needs to decentralize the disease and focus on the subject. "Taking care of subjects means helping them to relieve the suffering and granting them the support needed to overcome difficulties and cope with daily impasses". ${ }^{13: 251}$

These daily impasses take the form of pains and depression, listed quite frequently in the users' statements, which mainly affect elderly people and women. If a reductionist approach is adopted, patients will require medication interventions, consultations with specialists and exams: we see that he problem is more social, unstructured families, fights at home [...] when they come... I've got a pain in the back, then you see that that back pain is actually a fight at home, they're not doing well with the husband, not that well with the children, lives with the mother in law (Phy10); patients who consult a lot, they always have some disorder, anxious, depressed, not always a problem really, even a physical disease, but it's a problem of depression and anxiety really (CHA13); today actually, there's a lady here... her file is huge... she's here every day... one problem at a time. Today she's here because her son got together with a woman she wasn't really interested in and who's got an impaired daughter, living at her house and so... She comes and tells all of that, we listen and... then it starts, pain here, pain there, right? (Phy7).
As evidenced, in daily work at the FHS units, professionals are confronted with disease manifestations that are influenced by the social and family context. They seem sensitized with regard to the situations that contribute to the appearance of these symptoms, appointed as evils caused by social imbalances, including the lack of work, leisure, solitude. Despite perceiving them, however, it seems that they do not have technological devices to solve them, also because that would demand activities together with other social sectors. What we are confronted with a lot is the social problem, malnutrition, basic sanitation, untreated water, excessive births in some families (Phy11).

As the entry door to the public health sector, the Basic Health Units (BHU) turn into spaces where the population seeks answers to any needs affected. In combination with these social problems, it is observed that most users, considered "SUS dependent" have low education levels and act autonomously, as workers or domestic servants. Most interviewees' family income remains below two minimum wages and families include at least three people dependent on this income, besides their affiliation with FHS units to receive the Bolsa Familia, a public grant that is part of many interviewees' income.

\section{The (dis)continuity of care in view of de- mands by other sectors}

In this order, the needs presented here do not directly involve health services and professionals' capacity, demanding joint actions to be solved. In these cases, intersectoral interventions are due and individuals should take part in social, work and leisure projects, and also participate actively as co-responsible in these actions. Professionals need to understand the influence the sociocultural context exerts on the process of feeling healthy and getting ill, as well as on the importance of other public instances, like education, work and leisure, to cooperate with a view to solving the problems that emerge. ${ }^{14}$

Nevertheless, the discourse shows users who use SUS services with specific demands, that is, without effective participation according to each person's needs: when I've got no money to pay for a consultation, and sometimes there's the exam, then the only way is to turn to the SUS (U5); because a consultation, when we can, we pay a private one, when I can't I go to the SUS (U6); I buy the most expensive ones in the pharmacy because there aren't any here, but the 
ones they give here I prefer to get instead of buying. I only come here when I need the medicine (U12).

One of the users uses the service because he has got tuberculosis and upon the indication of the physician who diagnosed the disease: first, I went in Belo Horizonte, the physician there found out [tuberculosis diagnosis]. Then she said I had to follow him at the unit, then she asked me to go to the unit immediately (U2).

Based on the universality principle, the health service guarantees access to all, independently of whether the user has a private health insurance or not. The SUS absorbs users from all social groups, which consolidates the system as an equitable space of care for the population's health needs, reaffirming its democratic grounding principles.

The relation between the Family Health Team and the population covered needs to be based on the construction of bonding. This model is still accompanied by a fragmented practice though, centered on the production of medical-curative acts and interventions, in which disarticulation and users' countless complaints predominate. ${ }^{15}$

What is questioned, however, is how the service - population, professional - user bond is constructed in view of punctual and specific care. Bonding is considered as the continuous and longlasting relation of trust established between population and service, which permits the construction of longitudinal and integrated practices. This trust among user - professional - health team permits the construction of people's accountability and autonomy with regard to their living condition. ${ }^{16}$

These situations also reveal a fragmented system and reinforce inequalities in health service use. "That is, in the attitude to visit the services, get access and benefit from the care received, they reflect individual inequalities in the risk of illness and death, as well as differences in the individual's behavior towards the disease, besides the supply characteristics of the service each society offers to its members". ${ }^{17: 134}$

This evidences that the general population widely uses health actions like the treatment of tuberculosis, Hansen's disease or vaccination. Punctual service use, however, directly influences the relation between the State and health, so that the responsibility for health is somewhat removed from the State, at the same time as the private mentality is crystallized in the sector. ${ }^{18}$

This private mentality is confirmed when considering the following discourse: my father lost sight in one eye, it was cataract, his sight out of one eye was bad, he was falling all the time, hurting himself and awaiting surgery through the SUS, we were doing all we could but didn't achieve anything... until one day he had to find a way to pay for a private surgery, or he'd be blind until today. That happened, and it took more than two years, he was blind in one eye and all blurry in the other (U16).

Health professionals support and underline this attitude: I change the exam because the SUS does not have the specialty, as we don't and we want the person to be attended well, we change the exam, exceptionally we do it... you ask for an X-ray, that kind of stuff, change it, a joint ultrasound, we request the exam, the patient brings the request, then you transfer the data to a SUS request (Phy10).

These reports reveal that access to secondary care and communication among health care levels are permeated by obstacles that interfere in the care network's care flow. ${ }^{15}$ In view of delays or lack of answers to the affected needs, private or health insurance services are sought, which ends up reaffirming the State's removal of responsibilities for health demands. These attitudes reinforce social exclusion in access to health services for the people who do not have such "facilities" at their disposal. Thus, delays to schedule consultations and get exams discredits the problem-solving capacity of universal and equitable care in the public services and stimulates some people to turn to the private sector.

As demands for specialties are frequent, the situation becomes more severe, when professionals themselves start to suggest that users seek care at private health insurance services: in some cases, care is needed from a specialist, a physician forwards to a private one, normally, when the person has a health insurance, the nurse already attempts to ask help, a discount, through the SUS or even through an acquaintance, to help that person, to move faster... if the person doesn't have any insurance, doesn't have any financial possibility to pay, like, the person won't really! Then we attempt to assess those cases and find out if the person was able to go... many physicians accept it with medical forwarding, go for treatment away from home if the person has to take the exam somewhat urgently, because there is a queue there, so they give the person a discount, paying much cheaper and doing the exam, one way of speeding things up because, to go there, you'll really have to wait (CHA14).

Some professionals' conduct of referring users to private health insurance services, even if it involves a small fee and they get discounts in 
colleagues' private consultation services, although well-intended with a view to solving some users' needs, represent actual social apartheid in health. ${ }^{18}$

Therefore, this shows "the situation of continuing or even deeper social exclusion, the persistence of the current segmented, selective health system with service access according to market patterns, following the universalization of basic care in the SUS with the Basic Health Care Package (PAB). This package serves as a mechanism for expense control and rationalization of the sector, resulting in low social effectiveness". 18:46 Facts like this contribute to maintain the former sieve of public-private relations, in which the latter does not take interest in the establishment of more significant progress in the public sector.

To overcome this scenario, a new reference framework is imposed, based on the ethical commitment to life, including health promotion and recovery, with a view to guaranteeing access to the care needed, bonding, user co-accountability, comprehensive care and continuous monitoring of the results achieved. ${ }^{15}$ Thus, intersectoral, promotion, prevention, cure and rehabilitation actions should stimulate the prioritization of actions that respond to established social rights and should be guaranteed by the State, in accordance with the universality principle.

\section{FINAL CONSIDERATIONS}

The data permit reflecting on the subjective dynamics present in the situations that demand the use of health services. As perceived, feeling bad, feeling some pain gives users the key to talk about their problems and be heard. It is a kind of emotional appeal the body issues, sometimes validated by a professional, which grants them a space in the world and the certainty of being alive in this world-territory that surrounds them. The results also revealed that health service demands derive from the combination of social, individual and cultural factors prevalent in the population, and therefore requires that professionals adopt a look beyond the biological, understanding that the demands, initially presented as such, are actually a request for help in other psychological and social dimensions of the family.

In that sense, it is necessary to go beyond traditional practice, centered on the exclusivity of the biological dimension, to expand listening and reconsider the human perspective in the interaction between health professionals and users.
Former practices that weaken the principles of the SUS still continue, mainly the universality of access and longitudinality of care, as shown by forwarding or users' search for private services, as the city does not offer the services needed.

Hence, it is acknowledged that the symbolic reality allows users to grant meaning based on their individual experience and according to the social and cultural standards of their group. On the opposite, health professionals will need to modify some practices to be able to deal with these situations, which still cause estrangement, as they go beyond biological issues. The fundamental importance of acknowledging that cultural factors play a critical role in health care in all contexts is underlined, including in the formal health service delivery system. Health practices that are currently performed in the spaces of encounter need to be reconsidered and the technologies available to mitigate them need to be discussed, as not all needs turn into demands, but all demands refer to some kind of need that requires intervention.

The limitation the case study approach brings about is highlighted, which often does not permit generalization of the results found, as it focuses on a specific reality. It is highlighted, however, that one of the authors has been researching on the same theme in different cities in the State of Minas Gerais, with similar results. Hence, these studies can provide support to allow local managers to seek strategies that result in the care population's improved access, and that achieve problem-solving responses, including actions that are effective to enhance the population's quality of life.

\section{REFERENCES}

1. Costa EMA, Carbone MH. Saúde da família - uma abordagem interdisciplinar. Rio de Janeiro (RJ): Rubio; 2004.

2. Penna CMM, Brito MJM, Porto FR. Equity and resolution: of theory to construction in daily of health professionals. OBJN [online]. 2007 [acesso 2009 Out 10]; 6:. Disponível em: http://www. objnursing.uff.br/index.php/nursing/article/ view/1091

3. Penna CMM, Hemmi APA. Representações sociais de usuários sobre o atendimento em uma unidade de saúde da família. Cad Saúde Coletiva. 2009; 17(4):1075-91.

4. Giglio-Jacquemot A. Urgências e emergências em saúde: perspectivas de profissionais e usuários. Rio de Janeiro (RJ): Fiocruz; 2005.

5. Pinheiro R. Modelos ideais x práticas eficazes: um 
desencontro entre gestores e clientela nos serviços de saúde. Rio de Janeiro (RJ): IMS/UERJ; 1999.

6. Maffesoli M. O conhecimento comum: introdução à sociologia compreensiva. Porto Alegre (RS): Sulina; 2007.

7. Fontanella BJB, Ricas J, Turato ER. Amostragem por saturação em pesquisas qualitativas em saúde: contribuições teóricas. Cad Saúde Pública. 2008 Jan; 24(1):17-27.

8. Bardin L. Análise de conteúdo. Lisboa (PT): Edições 70; 2010.

9. Oliveira AMG, Siqueira, MEP, Altéa, PM, Saito, RXS. Avaliação em saúde para organização do trabalho na perspectiva do sujeito. In: Saito RXS, organizadora. Integralidade da atenção: organização do trabalho no programa saúde da família na perspectiva sujeitosujeito. São Paulo (SP): Martinari; 2008. p.83-116.

10. Ministério da Saúde (BR). Secretaria de Atenção à Saúde. Departamento de Atenção Básica. Saúde da família no Brasil: uma análise de indicadores selecionados: 1998-2004. Brasília (DF): MS; 2006.

11. Starfield B. Atenção primária: equilíbrio entre necessidades de saúde, serviços e tecnologia. Brasília (DF): UNESCO, MS; 2002.

12. Penna CMM. Realidade e imaginário no processo de viver de moradores de um distrito brasileiro. Texto Contexto Enferm. 2007 Jan-Mar; 16(1):80-8.
13. Lacerda A, Guimarães MB, Lima CM, Valla VV. Cuidado integral e emoções: bens simbólicos que circulam nas redes de apoio social. In: Pinheiro R, Mattos RA. Razões públicas para a integralidade em saúde: o cuidado como valor. Rio de Janeiro (RJ): IMS/UERJ, CEPESC, ABRASCO; 2007.

14. Kreutz I, Gaiva MAM, Azevedo RCS. Determinantes sócio-culturais e históricos das práticas populares de prevenção e cura de doenças de um grupo cultural. Texto Contexto Enferm. 2006 Jan-Mar; 15(1):89-97.

15. Viegas SMF, Penna CMM. O SUS é universal mas vivemos de cotas. Rev Ciênc Saúde Coletiva [online]; 2011 [acesso 2012 Jul 10]:. Disponível em: http:// www.cienciaesaudecoletiva.com.br/artigos/ artigo_int.php?id_artigo $=10220$

16. Queiróz ES, Penna CMM. Conceitos e práticas de integralidade no município de Catas Altas-MG. Rev Min Enferm. 2011 Jan-Mar; 15(1):62-9.

17. Travassos C, Viacava F, Fernandes C, Almeida CM. Desigualdades geográficas e sociais na utilização de serviços de saúde no Brasil. Ciênc Saúde Coletiva. 2000 Jan; 5(1):133-49.

18. Elias PE. Estado e saúde: os desafios do Brasil contemporâneo. São Paulo Perspec. 2004 Jul-Set; 18(3):41-6. 